\title{
Use of APAAP technique on paraffin wax embedded bone marrow trephines
}

\author{
WENDY N ERBER, JANET MCLACHLAN Haematology Department, Royal North Shore \\ Hospital, St Leonards, New South Wales, Australia
}

SUMMARY The immunoalkaline phosphatase (APAAP) technique was applied to the labelling of decalcified sections of formalin fixed, paraffin wax embedded bone marrow trephine biopsy specimens. A panel of monoclonal antibodies reactive with haemopoietic and epithelial antigens, which survive routine formalin fixation, was assessed on 72 cases of haematological malignancy (including acute and chronic leukaemias and lymphomas) showing bone marrow infiltration. The APAAP method showed clear distinct labelling of antigen positive cells without loss of antigens due to decalcification. Both normal or reactive single cells present in the sample and neoplastic cell populations could be identified morphologically and their antigenic phenotype and cellular origin, whether lymphoid or myeloid, established.

The application of the APAAP method to routinely prepared paraffin wax embedded trephines has many advantages over the assessment of specially prepared cryostat sections of bone marrow.

Monoclonal antibodies and immunocytochemical labelling techniques have proved valuable for phenotyping haemopoietic cells in peripheral blood smears and bone marrow aspirates ${ }^{1}$ but have been less widely applied to bone marrow trephine biopsy specimens. Until recently the assessment of trephine sections with monoclonal antibodies has been restricted to the analysis of undecalcified cryostat sections of fresh unfixed biopsy specimens. ${ }^{2}$ This necessitates special sample collection, trephine preparation, and cryostat sectioning of the calcified bone and is therefore an inconvenient method for routine immunocytochemical analysis. Ideally, therefore, a method that permits the phenotypic analysis of formalin fixed, decalcified, paraffin wax embedded bone marrow biopsy specimens is required.

Monoclonal antibodies which recognise antigens that survive routine tissue fixation and processing have recently become available. This new generation of antibodies has allowed definitive tumour diagnoses to be established in conventionally fixed lymphoid tissues $^{3-6}$ and has been successfully applied to the detection of lymphoid antigens in formalin fixed, decalcified bone marrow trephines using an immunoperoxidase labelling technique. ${ }^{78}$

In this study an immunoalkaline phosphatase (APAAP) labelling procedure and a panel of monoclonal antibodies to formalin resistant antigens was evaluated on conventionally processed decalcified bone marrow trephines from 72 cases of

Accepted for publication 25 May 1989 haematological malignancy. Using this method the phenotype of normal and neoplastic cells of lymphoid, myeloid, or epithelial origin could be established without incurring problems of endogenous enzyme, background labelling, or loss of antigens due to decalcification.

\section{Material and methods}

Trephine biopsy samples from the posterior iliac crest were collected from patients with a variety of disorders (table 1) attending the haematology department, Royal North Shore Hospital using Jamshidi or Islam needles. The trephine biopsy specimens were immediately placed in formol-acetic acid and fixed for six to 20 hours. Varying concentrations of acetic acid $(1 \%, 5 \%$ and $10 \%)$ were tested to ascertain the optimal fixative for preservation of cellular morphology and antigenicity. Other fixatives, including neutral buffered formalin, formol-acetic acid (5\%) in alcohol, and formol-saline, were assessed early in the study but were not pursued due to the poor cellular morphology or inadequate staining obtained. After fixation the slides were decalcified in RDO (Du Page Kinetic Laboratories Inc) or neutral ethylene diaminetetracetic acid (EDTA) for 24 hours. All trephine biopsy specimens were then embedded in paraffin wax. Sections of 3-4 $\mu \mathrm{m}$ thickness were cut, mounted on glass slides coated with gelatin and dried at $60^{\circ} \mathrm{C}$ for 20 minutes.

All cases were examined for their morphological characteristics after routine staining with haema- 
Table 1 List of bone marrow trephine samples studied

\begin{tabular}{lc}
\hline Disease & No of cases \\
\hline Acute lymphoblastic leukaemia & 11 \\
B lineage & 1 \\
T lineage & 8 \\
Acute myeloid leukaemia & 1 \\
Erythroleukaemia & 3 \\
Chronic myeloid leukaemia (blast crisis) & 10 \\
B cell chronic lymphocytic leukaemia & 3 \\
Hairy cell leukaemia & 1 \\
Waldenstrom's macroglobulinaemia & 18 \\
Non-Hodgkin's lymphoma & 4 \\
B lineage & 2 \\
T lineage & 4 \\
Hodgkin's disease & 4 \\
Reactive & 2 \\
Metastatic carcinoma & \\
Normal & \\
\hline
\end{tabular}

toxylin and eosin or Giemsa. The phenotype of the malignant cells in all cases studied had previously been established on bone marrow aspirate or peripheral blood samples.
Details of the monoclonal antibodies used in the study are listed in table 2.

All sections were initially dewaxed in xylene (10 minutes), followed by acetone (10 minutes), and then rehydrated in TRIS buffered saline (TBS). Enzymatic pre-digestion with $1 \%$ trypsin at $37^{\circ} \mathrm{C}$ for 10 minutes was then performed if required. The sections were then incubated with normal human AB serum to block non-specific antibody binding. Immunocytochemical staining was performed by the alkaline phosphataseantialkaline phosphatase (APAAP) method as previously described. ${ }^{111}$

\section{Results}

\section{IMMUNOCYTOCHEMICAL STAINING}

In all cases studied there was excellent preservation of cellular morphological detail and no background or residual endogenous alkaline phosphatase staining. Simultaneous visualisation of morphological detail and the antigen label allowed cells present even in only

Table 2 Monoclonal antibodies used in the study

\begin{tabular}{|c|c|c|c|}
\hline Antibody & $C D N o$ & Specificity & Source \\
\hline $\begin{array}{l}\text { Dako-LC } \\
\text { Dako-HLA-DR/alpha } \\
\text { Dako-4KB5 } \\
\text { KiB3 } \\
\text { Dako-UCHL1 } \\
\text { KP1 } \\
\text { Dako-elastase } \\
\text { Dako-M1 } \\
\text { Dako-MAC387 } \\
\text { Dako-GpIIIa } \\
\text { Ret40f } \\
\text { BerH2 } \\
\text { Cam 5.2 } \\
\text { Dako-CK }\end{array}$ & $\begin{array}{l}\text { CD45 } \\
\text { CD45R } \\
\text { CD45R } \\
\text { CD45R } \\
\text { CD15 } \\
\text { CD61 } \\
\text { CD30 }\end{array}$ & $\begin{array}{l}\text { Leucocyte Common } \\
\text { HLA-DR a chain } \\
\text { B restricted leucocyte common } \\
\text { B cells } \\
\text { T restricted leucocyte common } \\
\text { Myeloid/macrophage } \\
\text { Neutrophil elastase } \\
\text { Hapten X } \\
\text { Myeloid/macrophage } \\
\text { Platelet glycoprotein IIIa } \\
\text { Glycophorin C } \\
\text { Activation antigen } \\
\text { Cytokeratin } \\
\text { Cytokeratin }\end{array}$ & $\begin{array}{l}\text { Dakopatts } \\
\text { Dakopatts } \\
\text { Dakopatts } \\
\text { Professor Parwaresch } \\
\text { Dakopatts } \\
\text { DY Mason } \\
\text { Dakopatts } \\
\text { Dakopatts } \\
\text { Dakopatts } \\
\text { Dakopatts } \\
\text { DY Mason' } \\
\text { Dakopatts } \\
\text { Becton-Dickinson } \\
\text { Dakopatts }\end{array}$ \\
\hline
\end{tabular}

$\mathrm{CD}=$ Clusters of differentiation

$\mathrm{DRC}=$ Dendritic reticulum cells

Figs 1-8 show examples of formalin fixed, paraffin wax embedded bone marrow trephine sections stained with monoclonal antibodies and the APAAP technique and counterstained with haematoxylin.

Fig 1 A case of non-Hodgkin's lymphoma of $B$ cell origin stained with antibody $K P 1$. The positive reactive macrophages are easily visible contrasting with the negative tumour cells.

Fig 2 Another case of B cell non-Hodgkin's lymphoma stained with (a) $4 K B 5$ showing all the neoplastic cells to be positive; and (b) UCHL1 showing a small number of reactive lymphocytes (arrowed).

Fig 3 Hairy cell leukaemia in which the malignant hairy cells were not detected in the trephine section stained with haematoxylin and eosin. This figure shows staining with antibody KiB3 easily showing the hairy cells of B cell origin.
Fig 4 Acute myeloblastic leukaemia stained with antibody KP1 showing positive staining of the leukaemic blast cells.

Fig 5 Trephine section from a case of chronic granulocytic leukaemia in blast crisis stained with Dako-GpIIIa. The megakaryoblastic origin of the blast cells (arrowed) is shown (despite the morphological distortion due to marrow fibrosis) by their reactivity with this platelet glycoprotein IIIa antibody.

Fig 6 A case of erythroleukaemia stained with the glycophorin C antibody Ret40f.

Fig 7 Hodgkin's disease infiltrating the marrow showing positive labelling of the Reed-Sternberg and Hodgkin cells with BerH2.

Fig 8 A large clump of carcinoma cells in the marrow from a case of carcinoma of the breast stained with Cam5.2. 

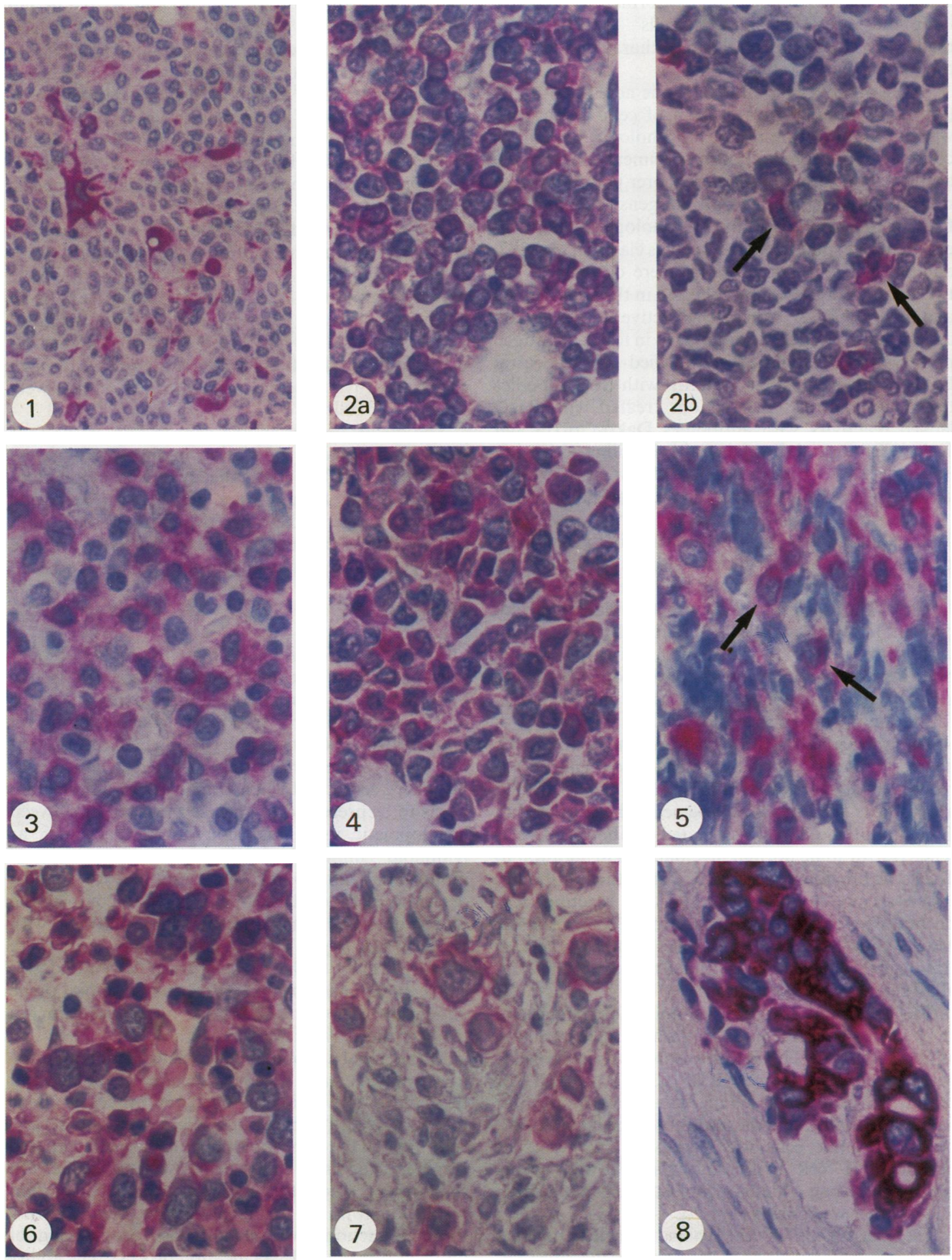
small numbers - for example, normal or reactive lymphoid cells, Reed-Sternberg cells-to be identified readily by their morphological characteristics and their phenotype established (fig 1).

Of the fixatives tested, $5 \%$ acetic acid in formalin (v/v) gave optimal preservation of cellular antigens without any compromise of morphological detail. In contrast, the trephine biopsy specimens fixed in $1 \%$ acetic acid in formalin showed poorer preservation of morphology but retained all antigens, and in those fixed in $10 \%$ acetic acid the morphological detail was excellent but some antigens (such as elastase, Mac387, and platelet glycoprotein IIIa) were destroyed. The two decalcification regimens tested in the study, RDO and neutral EDTA, were both effective decalcification agents but showed some differences in terms of antigen preservation. Trephines decalcified with neutral EDTA showed positive staining with all antibodies tested. In contrast, the sections treated with RDO lacked reactivity with antibodies Dako-GpIIIa and Dako-elastase and showed weaker labelling with other antibodies. No differences in cellular preservation were seen between these two decalcification agents.

Thirteen of the 14 monoclonal antibodies assessed in this study showed positive labelling in the routinely processed trephine sections without the need to unmask antigens with proteolytic enzymes, such as trypsin. The one exception was the platelet glycoprotein IIIa antibody which required pre-digestion with trypsin to show positive labelling of normal platelets and megakaryocytes and neoplastic megakaryoblasts (in one case of megakaryoblastic transformation of chronic granulocytic leukaemia).

The antibodies used in the study showed variable degrees of lineage specificity when tested on normal or reactive bone marrow trephines. The $B$ cell associated antibodies 4KB5 and $\mathrm{KiB} 3$ seemed to be restricted to $B$ cells, but the T cell associated antibody UCHL1 reacted with some normal myeloid cells in addition to $T$ cells, as previously described. ${ }^{12}$ The other antibodies tested seemed to be lineage specific reacting with normal myeloid and monocytic cells (KP1, elastase, Mac387 and M1), erythroid cells (Ret40f), or cells of the megakaryocyte lineage (platelet glycoprotein IIIa) at all stages of differentiation.

The acute and chronic lymphoid malignancies all showed positive labelling for the leucocyte common antigen (CD45). The B cell disorders were positive with HLA-DR and either 4KB5 (CD45R) or KiB3, or both (fig 2), and the $T$ cell malignancies were positive for UCHL1 (although the intensity of the label and the percent positive cells was variable). Two cases of peripheral $\mathrm{T}$ cell lymphoma also showed strong positive labelling of most neoplastic cells with $\mathrm{KiB3}$, and another was positive for HLA-DR.

The blast cells in the cases of acute myeloid leukaemia studied were positive with the myeloid/ macrophage antibody KP1 (fig 4) and HLA-DR but negative with the $B$ and $T$ cell antibodies. The blasts were also positive with Dako-elastase, Mac387, and Dako-M1 in the cases in which the trephines had been decalcified in EDTA, but not those decalcified in RDO. In the case of acute megakaryoblastic transformation of chronic myeloid leukaemia (decalcified in EDTA) the blast cells were positive with the platelet glycoprotein IIIa antibody (fig 5) and the neoplastic erythroblasts in the case of erythroleukaemia (both EDTA and RDO decalcification) showed reactivity with the glycophorin C antibody Ret40f (fig 6).

In the two cases of Hodgkin's disease with bone marrow infiltration the Reed-Sternberg cells were strongly positive (fig 7) with antibodies BerH2 (CD30) and Dako-M1 (CD15). These cells were unreactive with the $B$ and $T$ cell associated antibodies, although the reactive lymphocytes present in the section were positively labelled.

The metastatic carcinoma cells in two of the four cases of neoplastic infiltration in the marrow were positively labelled with the two anti-cytokeratin antibodies (fig 8) and were negative for leucocyte common antigen. The other two cases studied, both small cell lung carcinomas, lacked reactivity with the anti-cytokeratin and leucocyte common antibodies.

\section{Discussion}

Over the past 15 years bone marrow trephine biopsy specimens have become more widely used in the investigation of haematological disorders. Their role has been particularly important when attempts at marrow aspiration yield a dry tap, when cells present only in small numbers are to be assessed (such as ReedSternberg cells), and when bone marrow architecture needs to be preserved to analyse the relation between haemopoietic tissue and bony trabeculae, such as lymphoid infiltrates. With the availability of monoclonal antibodies and immunocytochemical detection methods it became possible to combine the morphological preservation of the marrow with antigen labelling. ${ }^{2}$ These methods, however, were initially limited to the study of fresh frozen undecalcified bone marrow sections because most tissue antigens were lost in the process of routine formalin fixation and paraffin wax embedding.

Monoclonal antibodies which detect formalin resistant antigens have recently become available, and these allow conventionally fixed and processed tissue to be analysed. ${ }^{49}$ These antibodies have been successfully applied to the phenotyping of routinely prepared formalin fixed tissue using the APAAP technique. ${ }^{34}$ In the present study this method gave equally good results on formalin fixed, decalcified bone marrow trephine sections without the loss or masking of antigens due to the decalcification process. The ability 
to stain these routinely prepared sections has many advantages over the study of cryostat sections of fresh, unfixed undecalcified trephine samples: there is no need for special sample collection, snap freezing, and cutting of sections in a cryostat as the routinely processed material is studied; morphological detail is optimally preserved as the trephine biopsy sample has been fixed in the conventional manner; and the paraffin wax embedded material can be stored for a long time at room temperature.

The choice of both the fixative and decalcifier were important because they affected optimal cellular morphology, antigen preservation, and the resultant APAAP staining quality. In this study $5 \%$ acetic acid in formalin was superior to the other fixatives tested, giving excellent staining quality together with good morphological detail. In contrast to the findings of other published reports, ${ }^{7}$ there are differences in the effects of decalcification agents on the immunoreactivity of cellular antigens. Treatment of the trephine biopsy specimens with the commercial decalcifier RDO resulted in the loss or partial destruction of diagnostically useful antigens such as elastase and platelet glycoprotein IIIa, but all antigens seemed to survive neutral EDTA treatment. We therefore recommend $5 \%$ acetic acid in formalin as the fixative and neutral EDTA as the decalcification agent of choice for bone marrow trephines if immunophenotyping of these samples using the APAAP technique is to become routine.

Most neoplastic bone marrow infiltrates were successfully phenotyped and classified on the trephine biopsy specimens with the panel of monoclonal antibodies used in the present study. Lymphoid malignancies of $B$ cell origin could be clearly identified because of their reactivity with HLA-DR and one or more of the $B$ cell associated antibodies, and the $T$ cell malignancies with antibody UCHLl. During the course of the study two cases of B cell malignancy (hairy cell leukaemia and neoplastic angioendotheliomatosis), in which the neoplastic cells were virtually impossible to detect in the trephine sections stained with haematoxylin and eosin, were assessed. The neoplastic cells were easily visualised when stained with the B cell antibodies (fig 3), showing the value of the APAAP labelling method for the detection of small numbers of infiltrating cells in the marrow.

The acute myeloid leukaemias were easily distinguished from those of lymphoid origin by their reactivity with the myeloid/macrophage associated antibody KP1 and lack of labelling with the lymphoid related antibodies. Cases with leukaemic megakaryoblasts and with neoplastic erythroblasts could be identified. Other malignant marrow infiltrates studied-Hodgkin's disease and metastatic carcinoma-could also be successfully phenotyped in most cases even when the neoplastic cells were only present in small numbers.

In conclusion, we have shown that the APAAP technique is a valuable method for the immunophenotypic analysis of haematological malignancies in routinely prepared decalcified bone marrow trephine biopsy specimens. The method gives results comparable with those obtained on formalin fixed tissue sections, confirming that the process of decalcification does not cause masking or further destruction of cellular antigens. This work is now being continued to assess the value of the method in establishing diagnoses on bone marrow trephines.

We are grateful to the laboratories listed in table 2 for their generous gift of monoclonal antibodies, the anatomical pathology department, RNSH for preparing the bone marrow trephine samples for analysis, and Jane Norris for typing the manuscript. This work was generously supported by Dakopatts and the Leukaemia Research Fund, RNSH.

\section{References}

1 Erber WN, Mynheer LC, Mason DY. APAAP labelling of blood and bone marrow samples for phenotyping leukaemia. Lancet 1986;i:761-5.

2 Falini B, Martelli MF, Tarallo F, et al. Immunohistological analysis of human bone marrow trephine biopsies using monoclonal antibodies. Br J Haematol 1984;56:365-86.

3 Davey FR, Gatter KC, Ralfkiaer E, Pulford KAF, Krissansen GW, Mason DY. Immunophenotyping of non-Hodgkin's lymphoma using a panel of antibodies on paraffin embedded tissues. Am J Pathol 1987;129:54-63.

4 Mason DY, Gatter KC. The role of immunocytochemistry in diagnostic pathology. J Clin Pathol 1987;40:1042-54.

5 Norton AJ, Isaacson PG. Immunocytochemical study of T-cell lymphomas using monoclonal and polyclonal antibodies effective in routinely fixed wax embedded tissues. Histopathology 1986;10:1243-60.

6 Norton AJ, Isaacson PG. Detailed phenotypic analysis of B-cell lymphoma using a panel of antibodies reactive in routinely fixed wax-embedded tissue. Am J Pathol 1987;128:225-40.

7 Athanasou NA, Quinn J, Heryet A, Woods CG, McGee JO'D. Effect of decalcification agents on immunoreactivity of cellular antigens. J Clin Pathol 1987;40:874-8.

8 Hall PA, Lindeman R, Butler MG, Amess JAL, D'Ardenne AJ. Demonstration of lymphoid antigens in decalcified bone marrow trephines. J Clin Pathol 1987;40:870-3.

9 Feller AC, Wacker HH, Moldenhauer G, Radzun HJ, Parwaresch MR. Monoclonal antibody $\mathrm{Ki}-\mathrm{B} 3$ detects a formalin resistant antigen on normal and neoplastic B cells. Blood 1987;70:629-36.

10 Gatter KC, Cordell JL, Turley H, et al. The immunohistological detection of platelets, megakeryocytes and thrombi in routinely processed specimens. Histopathol 1988;13:257-67.

11 Cordell JL, Falini B, Erber WN, et al. Immunoenzymatic labelling of monoclonal antibodies using immune complexes of alkaline phosphatase and monoclonal anti-alkaline phosphatase (APAAP complexes). J Histochem Cytochem 1984;32:219-29.

12 Norton AJ, Ramsay AD, Smith $\mathrm{H}$, et al. Monoclonal antibody (UCHL1) that recognises normal and neoplastic $T$ cells in routinely fixed tissues. J Clin Pathol 1986;39:399-405.

13 Erber WN, Breton-Gorius J, Villeval JL, Oscier DG, Bai Y, Mason DY. Detection of cells of megakaryocyte lineage in haematological malignancies by immuno-alkaline phosphatase labelling cell smears with a panel of monoclonal antibodies. $\mathrm{Br} J$ Haematol 1987;65:87-94.

Requests for reprints to: Dr W Erber, Haematology Department, Royal North Shore Hospital, St. Leonards, N.S.W. 2065, Australia. 